\title{
Evaluating a Pilot Course Student Support and Development - A 360 Degree Professional Learning Opportunity
}

\author{
Joanna Peters \\ Director, Student Services \\ Katherine Main \\ Senior Lecturer \\ Lexie Mooney \\ Consultant and Facilitator \\ Regine Ip \\ Evaluation and Service Improvement Officer, Student Services \\ David Noonan \\ Business Development Officer, Professional Learning Hub \\ Griffith University
}

\begin{abstract}
While there are several formal "for credit" professional preparation courses for people working in or aspiring to work in student support and development roles in higher education in the United States of America (USA) and the United Kingdom (UK), to date, no such qualification has been available in Australia or New Zealand. In 2018, a new Student Support and Development course (the Course) was piloted though Host University, Australia. The course was offered as a fully on-line course, either as a credit pathway to the Graduate Certificate in Professional Learning (Host University), or purely for professional development for those not wishing to undertake formal assessment items. A total of 39 participants initially enrolled in the Course with 29 completing some or all of the Course components. On completion of the course, $72 \%(N=21)$ of participants received a Certificate of Completion with almost $43 \%(N=9)$ of those undertaking additional tasks and receiving $10 \mathrm{CP}$ credit (AQF Level 8) into further tertiary study. Twenty-eight percent of participants $(N=8)$ received a Certificate of Participation for completing some of the course modules. Overall feedback indicated that the Course was relevant, would positively impact practice, and reported a general satisfaction with the mode and delivery of the Course. However, it was also noted that the diversity of participants' prior experience needed to be considered and that the course needed to be more focused to provide multiple pathways for differing levels of experience and training. Other insights together with reflections of staff facilitating delivery, will be used to inform planning for, and future development of the Course.
\end{abstract}

I am really enjoying it, it has already opened-up many ideas and actions for me - I can't believe I haven't studied this sooner ${ }^{1}$

\section{Keywords}

Student support, professional development, formal training; student affairs, student services

\section{Introduction}

Post-secondary education institutions (e.g., universities, VET) in Australasia commit significant resources to the provision of student support and development services and programs [SSDSP]. These services and programs include, but are not limited to, learning and academic skills assistance, personal and mental health support, financial aid and financial literacy programs, chaplaincy, disabilities support and careers and employment services. Funding for these sorts of services comes from base grants, student fees (Department of Education and Training, 2018) and identified program sources (Department of Industry, Innovation \& Science, 2019).

\footnotetext{
${ }^{1}$ Unsolicited feedback from a Course participant via email to facilitator 
Legislation in Australia stipulates the requirement for the provision of SSDSP for all students attending post-secondary institutions, and specifically in relation to international students, with the expectation that these programs and services are quality assured, audited and subject to internal and external review. The Tertiary Education Quality Standards Agency (TEQSA) sets standards for the provision of these services and programs and has issued guidelines for institutions to demonstrate they have appropriate services and programs in place around student wellbeing and safety. Similarly, in New Zealand, the Tertiary Education Strategy outlines the expectations for institutions to support the access persistence and success of post-secondary learners (Ministry for Education, New Zealand Government, 2018).

Data shows that hundreds of thousands of university students in Australia and New Zealand access SSDSP every year and, through their fees or student contribution, pay towards their continued operation (Australian Department of Education and Training, n.d.; New Zealand Tertiary Education Commission, n.d.). The delivery of these programs and services requires a significant workforce of professional and support staff who work in student support and development units across these two countries. These support and development units may vary in structure and in their location within their institution, but the nature of services and programs offered is relatively common across the sector and, indeed, globally (Manning, Kinzie, \& Schuh, 2014).

With a growing focus on student outcomes for institutional funding and for recruitment, increasing attention has been given to the role and impact of student support and development services. In particular, how these services work in collaboration with faculty and other agents, in supporting student recruitment, transition, engagement, retention and graduate employment has been under investigation (Coates \& Ransom, 2011; Kezar, 2003, 2011; Kezar, Eckel, Contreras-McGavin \& Quaye, 2008; Ludeman, Osfield, Iglesias, \& Oste, \& Wang, 2009; Stone, 2005; Stone, 2005a). The complexity of the roles in SSDSPs and the ability of those to be able to work from the micro level (i.e., with individual students) to a macro level (i.e., across the whole of the institution and beyond) requires a range of specialised and contextualised skills.

Importantly, with SSDSPs under scrutiny, the importance of appropriate training and qualifications for those entering professional and support roles in student support and development units cannot be overstated. Staff working within these units have been given a remit to deliver a broad range of services and, as such, are required to have a broad range of knowledge and skills to be effective in their roles. Equally important is the requirement for appropriate and high quality continuing professional development for these practitioners, to ensure effective execution of their responsibilities.

Continuing and effective professional development can take a variety of forms including attendance at conferences and symposia, membership of professional associations, subscriptions to relevant journals, on-the-job training, mentoring and coaching, networking, professional supervision and formal study. However, the specific focus of this paper is on opportunities for professional development through formal study. To date, formal study options available in Australia and New Zealand for both preparation and for continuing professional development for those working in student support service units have been within (a) the expectations of a discipline area (e.g., psychology, social work), (b) in a generic "tertiary skills" domain (e.g., Masters in Business Administration, leadership) or (c) in a "higher education" qualification (e.g., Graduate Certificate in Higher Education).

\section{Methodology}

\section{The Student Support and Development Course (the Course)}

Since the early 1990s, the executive and members of ANZSSA (Australian and New Zealand Student Services Association) have consistently stated the need for a formal preparation course for those 
working in student support and development units in Australian and New Zealand universities. Given that such programs in the USA and UK are full degree qualifications (Graduate Diploma or Masters), there was a recognised need for the development of a formal qualification to support and enhance the work of staff working in SSDSPs in Australia and New Zealand. ANZSSA decided to develop a single Student Support and Development Course (10 CP, AQF Level 8), that could articulate into the Graduate Certificate in Professional Learning offered through a host university.

The development and offering of the Student Support and Development course as a single unit of study required careful consideration of the content that needed to be prioritised. The Course was structured in four modules, namely: Module 1: Student development theory; Module 2: Models of student support, development and advising; Module 3: Supporting and developing students from diverse backgrounds; Module 4: Understanding our role in student support, development and/or advising. These topics reflected the focused content of graduate preparation programs for student affairs' professionals in the US (NASPA Graduate Program Directory). The content was also contextualised for those operating in the Australian and New Zealand educational landscapes.

\section{Data collection for program evaluation}

In broad terms there are three functional types of program evaluation: needs assessment (to determine the value proposition of initiating a new program); formative evaluation (for monitoring implementation and process, to improve these) and summative evaluation (to measure the outcome or impact of the program. As noted above, the needs assessment had already been undertaken as noted through the absence of availability of formal qualification programs across Australasia as well as being a consistent topic raised by the ANZSSA executive and membership. As such, both formative (to inform delivery) and summative (to assess value and impact) evaluation was deemed important. The evaluation used a mixed methods approach drawing on analysis of both quantitative and qualitative feedback (Creswell, 2017; Teddlie \& Tashakkori, 2009). Participant feedback was received via a number of sources including an Exit Survey, a Module Review Question at the end of each Module, and unsolicited feedback given directly to facilitators via emails. Ethics approval was gained through the host university for the survey.

\section{Participants}

Thirty-nine people enrolled initially in the Course, however, two withdrew due to a lack of funding; two withdrew due to personal (medical) circumstances; six enrolled and accessed the Course learning platform (Blackboard) but did not engage beyond that with any of the materials on the site. Although these six potential participants enrolled in the course, the course statistics showed that they had not engaged in any of the course materials, nor had they provided any comment or feedback on the course. As such, these six participants were excluded from the results to provide a more accurate reflection of participants' engagement and perceptions of the course. In total, 29 participants actively engaged with the Course.

\section{Profile of respondents}

Of respondents to the Exit Survey, 73\% identified as female $(\mathrm{N}=21)$ and $27 \%(\mathrm{~N}=8)$ as male; the median age was 34 years (age range 23-48 years); and the median number of years in student support and development roles was four years (range 1-12 years). For 50\% of respondents their highest level of education was a postgraduate qualification (doctorate; masters, graduate diploma) and the remaining 50\% had an undergraduate degree. Eighty percent of respondents $(\mathrm{N}=23)$ said they did the Course purely for their own professional development with $71 \%(\mathrm{~N}=20)$ of respondents reporting that they had not done any professional development training in this area before. The wide range in pre-Course education level of participants and differing levels of experience in a student support and development role might account for the likely different goals of the for credit versus for professional development groups. Therefore, caution is warranted in interpretation of survey results and participant 
feedback about certain aspects of the Course.

\section{Exit survey}

The Exit Survey was modelled after a similar survey used by the Professional Learning Hub for other professional development courses (Author), and also included questions (in Section 1) that reflected the items in the host university's standard evaluation measures for student assessment of learning and teaching - namely a six item Student Experience of Course (SEC) scale, and a five item Student Experience of Teaching scale (SET). This approach was taken to enable comparison of feedback for this Course against that recorded for equivalent postgraduate on-line courses for $10 \mathrm{CP}$ credit delivered at the host iniversity. Demographic data of respondents was also sought, as was their ratings on two general questions about overall value of the Course to them, and likelihood they would recommend it to others. Comments were also invited about what they liked about the Course (overall) and the "teaching/instruction", what could be improved, and "any other comments".

\section{Response rate}

Seventeen participants responded to the Exit Survey, a response rate of 59\% of people who engaged with the Course. While $70 \%$ of those who did the Course for professional development responded to the Survey, only one third of those who did the Course for credit did so. As questions relating to assessment were most relevant to the latter group, this was disappointing, and caution therefore is needed in extrapolating too much from this feedback. This response rate of the "for credit" group however is comparable with the range of response rates at Host for postgraduate on-line courses over the period 2014-2018 (34\%-45.6\% for SEC items, and 25.4\% - 43.3\% for SET items).

It was anticipated that those who did the Course for credit were likely to have held different expectations, and had different experiences as participants, from those who did it for professional development.

\section{Results and comments on specific datasets}

Seventy-two percent $(N=21)$ of participants received a Certificate of Completion (significant engagement with material across all four modules) with almost $43 \%(\mathrm{~N}=9)$ of participants also completing the formal assessment items to achieve the offered $10 \mathrm{CP}$ credit. The remaining eight participants (28\%) were provided with a Certificate of Participation for completion of at least one of the modules. Differing levels of participation may have been due, in part, to the broad range of participant SSDSP experience, with some participants electing to only complete the modules most relevant to their learning. However, further investigation into potential reasons for this difference is warranted.

Section 1 of the Exit Survey asked 12 questions about scope, content, format and delivery of the Course. The questions were presented using a five-point Likert rating scale (SD (strongly disagree); $\mathrm{D}$ (disagree); N (neutral); A (agree); SA (strongly agree) and aligned with standard SEC (student evaluation of a course) and SET (student evaluation of teaching) evaluation questions used for other Host on-line postgraduate courses. Section 2 asked a series of questions to measure the impact of the Course in terms of professional development of learners. The last section of the Survey asked for demographic information from participants as well as their professional profile (qualifications and work experience). Results are discussed below.

\section{Section 1 - Scope, content, format and delivery of the Course.}

Tables 1 and 2 below show the responses to these questions, for all respondents, and also for those respondents who did the Course for credit. The mean ratings for both the SEC and SETs in the Course compared as equal to or above comparable online courses offered at a tertiary level (host university, 2014-2018). 
Table 1: SEC - Student experience of course questions - mean all respondents and "for credit" respondents

\begin{tabular}{|c|c|c|}
\hline Question & All & For Credit \\
\hline 1. Overall, I am satisfied with the quality of the Course & 3.6 & 4.3 \\
\hline $\begin{array}{l}\text { 2. The teaching (instructors, on-line resources) was generally } \\
\text { effective in helping me to learn }\end{array}$ & 3.5 & 4.3 \\
\hline 3. This Course engaged me in learning & 3.5 & 4.3 \\
\hline 4. I received helpful feedback on my assessment & 3.6 & 4.0 \\
\hline $\begin{array}{l}\text { 5. (a)The assessment information (tasks, instructions, marking } \\
\text { criteria) was clear }\end{array}$ & 3.5 & 4.7 \\
\hline $\begin{array}{l}\text { 5. (b) The assessment tasks were fair (related to course content, } \\
\text { reasonable weighting) }\end{array}$ & 3.4 & 4.0 \\
\hline 6. The Course was well organised & 3.6 & 4.7 \\
\hline
\end{tabular}

Table 2: SET - Student experience of teaching questions - mean all respondents and "for credit" respondents

\begin{tabular}{lcc}
\hline Question & All & For Credit \\
\hline $\begin{array}{l}\text { 1. Overall, I am satisfied with the teaching of the instructor (mini- } \\
\text { lectures and guest lectures) }\end{array}$ & 3.7 & 4.3 \\
$\begin{array}{l}\text { 2. The instructors (mini-lectures and guest lectures) presented } \\
\text { material in a clear and organised way }\end{array}$ & 3.7 & 3.3 \\
$\begin{array}{l}\text { 3. The instructors (mini-lectures and guest lectures) presented } \\
\quad \text { material in an interesting way }\end{array}$ & 3.5 & 4.3 \\
$\begin{array}{l}\text { 4. The Course facilitators treated participants with respect } \\
\text { 5. The instructors (mini-lectures and guest lectures) showed good } \\
\text { knowledge of the subject matter }\end{array}$ & 4.1 & 5 \\
\hline
\end{tabular}

\section{Comment}

Ratings from those participants doing the Course for credit were higher in all but one instance (SET - Item 2) than for those doing the Course purely for professional development. There may be various explanations for this including those in the "for credit" group having a stronger engagement with the Course, and closer scrutiny of content and delivery as this related to "passing" it. It could also possibly reflect more familiarity of this group with equivalent Courses at comparable levels. Ratings from the "for credit" group were also equal to or higher than comparison scores (i.e., for all postgraduate courses delivered on-line at the host university over the period 2014-2018), for all the SEC items and for all but the same SET item (i.e. SET item 2).

Ratings on SET Item 2 suggest that all respondents and more especially the "for credit" group were less favourable about the clarity and organisation of how the Course content was presented. Some quotes from participants might go some way to shed light on what this was referring to:

I understand the potential usefulness of having a number of shorter 'mini-lectures' interspersed with additional material - to the extent that breaking the information down into smaller chunks could make it easier to set aside short periods of time to the material. However, this became possibly the biggest 
deterrent for me to actually work through the course in small chunks - because I couldn't easily tell where I left off last and what I had done before.

PROGRESS INDICATOR and flexible navigation within the content would have had a huge help!

Responses to a question elsewhere on the Exit Survey asking about whether the optional assessment items were relevant to their professional practice (see below) showed that $41 \%$ agreed/strongly agreed that they were, and that 53\% were "unsure" (presumably reflecting the fact that many respondents did not do the assessment items).

\section{Overall value and likelihood to recommend.}

The Exit Survey also invited participants to rate the Course overall in terms of value to them as a student support and development professional, and to say how likely they would be to recommend the Course to others ( 5 being highest and 1 being lowest for both scales). The median score for the "value to them as a professional" was 4 . The median score for "likelihood to recommend" was 4. These results demonstrate the value in the overall Course as a form of professional development for this cohort, and more generally for SSDSP colleagues.

\section{Qualitative feedback}

The Survey also asked participants to provide comments (open ended question format) about what they found "particularly good" about the Course overall; how it could be improved; the aspects of "teaching" most valuable to their learning; and how the teaching could be improved. A general "any other comments" question was also included - although, through a glitch in the survey design, this question was posed before the other open-ended questions. This anomaly in the survey design may have contributed to repetition and some frustration for participants who had already provided "specific" feedback in the "general" question. Feedback to the "general" question is shown in Table 3 categorised as "strengths" (what they liked) and "areas for improvement". Comments tended to reflect what was expressed in the other open-ended text questions addressing the same sorts of questions.

Table 3. Key themes from qualitative feedback

\begin{tabular}{|c|c|}
\hline \multicolumn{2}{|c|}{ Participant feedback } \\
\hline $\begin{array}{c}\text { Strengths/positive aspects of teaching most } \\
\text { valuable to learning }\end{array}$ & $\begin{array}{c}\text { Areas for improvement (general and/or for } \\
\text { teaching) }\end{array}$ \\
\hline Learned new frameworks and perspectives & $\begin{array}{l}\text { Needed a longer time frame to go through Course } \\
\text { materials, not friendly to people with full-time work }\end{array}$ \\
\hline $\begin{array}{l}\text { Excellent and relevant, and essential to all people } \\
\text { working in this field }\end{array}$ & Spent too much time on theory compared to practice \\
\hline $\begin{array}{l}\text { Great professional development for new people in the } \\
\text { field }\end{array}$ & Quite intensive and condensed \\
\hline Concrete examples to illustrate abstract conceptions & $\begin{array}{l}\text { Some students who have background knowledge } \\
\text { found some content repetitive }\end{array}$ \\
\hline $\begin{array}{l}\text { Open response text boxes help students to stop and } \\
\text { think, encouraging critical reflection }\end{array}$ & Technical issues with the platform itself \\
\hline \multirow{4}{*}{$\begin{array}{l}\text { Learned strong foundational knowledge of student } \\
\text { development and support the practice is informed by } \\
\text { theory and have better understanding of the reasoning } \\
\text { of the practice and ways of improving services }\end{array}$} & Longer lectures \\
\hline & Some content of lectures too shallow \\
\hline & Australia-centric - need to integrate NZ content \\
\hline & $\begin{array}{l}\text { Some content assumed students had wide and deep } \\
\text { background knowledge; while some seemed to be for } \\
\text { complete novices }\end{array}$ \\
\hline
\end{tabular}

Journal of the Australian and New Zealand Student Services Association: 
A thematic analysis of the feedback to each of these questions, and some examples of comments are given below (note that sometimes comments reflecting these themes were in response to different questions - or the "general feedback" question).

\section{What did you find particularly good about this Course?}

Respondents liked the incorporation of theory and practice; the lectures and videos; research and best practice from elsewhere; learning about context; and opportunities to critically reflect on the learning materials and their own practice.

I liked the layout of it, i.e. how it was structured and flowed from theoretical perspectives into practical applications.

The structure flowed well, i.e. went from a broad historical overview of theories into more practical ways to apply SSD

The questions where you needed to reflect on your practice - really good reflection opportunities

How could this Course be improved? (Including responses from the 'general feedback' question)

Areas for improvement that were suggested included: technical issues with the way the learning platform worked (difficulties moving through modules and "bookmarking" progress made; sound quality on some videos); the way Collaborate sessions were sequenced; perceived redundancy (repetition and/or irrelevance) of some material; the content of the mini-lectures being delivered orally (video) as well as on downloadable slides; perceived under-representation of New Zealand specific content; lack of (individual vs collective) feedback on participant reflection activities in the Course site (non-assessable); and access to Course content no longer being available after the Course closed.

The platform was not very intuitive - one example being that it didn't indicate how far you'd got, to find which page you'd got to you had to flick through each page of the module, every time you logged in.

Some of the polls also didn't display properly or didn't seem to save my responselupdate the pie chart.

The platform was very limiting in terms of delivery and interaction.

If you didn't do the assessments, there was no feedback provided throughout the course - it would be nice to have a feedback summary in answers were provided for the questions - I think this would have help with learning the content.

What aspects of the "teaching" were most valuable to your learning?

Respondents listed a number of things that were valuable to their learning including: the minilectures, Discussion Board; activities that forced critical self-reflection; opportunities for sharing observations and practice; and concrete examples of abstract concepts.

The lectures/videos were fantastic and very informative.

The mini-lectures. Once I listened to that, it was very obvious what the topic was going to be about.

Encouraging us to share our observations and practice experience 
I enjoyed how all presenters provided concrete examples, even when the content was somewhat abstract. To me, I found this very beneficial.

\section{How could the "teaching" be improved?}

Suggestions for improving instruction included: changing the time spent on different aspects of the Course (e.g., theory versus more "practice-focussed" content); range of "depth" of content presented; longer and more in-depth lectures; more variety/interactive material.

I'm not sure it (the teaching) could be improved

Longer lecture videos. More in-depth.

Maybe the teaching could be more 'interactive' so to speak. Instead of talking through a PPT presentation, teaching could embed more engaging means of delivery, e.g. pause lecture and do an activity, or a video of good practice that reflects the dot points in the PPT

\section{Other feedback (general, and drawn from other questions where related to overall impact)}

Overall, my practice is informed by theory now and I have a much better understanding of why we do the things we do and how can we improve.

I thought this course was excellent and very relevant to student services/student affairs staff. I think anyone wanting to work at a university should undertake this training.

Overall this course provided great PD in SSD. For me, someone who is very much new in the space, I learned a great deal and gained some valuable insights that will help me now, and in to the future.

I wish the course materials can be accessed any time after the course completion

\section{Feedback on Module Review question}

As participants had completed each Module, they were invited to provide feedback on the content they had just covered. Participants were asked to comment in relation to good aspects and areas for improvement and these comments were entered directly into the learning platform in the same way as participant answers to questions posed, or responses to reflective exercises were entered. This continuous feedback was useful for facilitators to gauge participant involvement in, and satisfaction with the Course as they went along.

Fourteen participants (48\%) provided qualitative feedback in relation to good aspects and areas for improvement on Module 1, eight (28\%) participants provided feedback on Module 2, seven participants (24\%) provided feedback on Module 3, and six participants (21\%) provided feedback on Module 4.

Different participants had quite different reactions to the level or depth at which the Course content had been pitched. Some found it too basic, while others said too much prior knowledge was assumed. This contradiction was a recurring theme from the feedback on each Module Review Question and in the Exit Survey. The wide range of prior educational levels of people enrolled in the Course (from doctoral level to secondary school level), and/or the diversity of SSDSP experience (from novice to very experienced) might account for the disparity of views.

Other related themes from the Module Review Question feedback aligned with the overall feedback in the Exit Survey and included concerns around (a) the amount of content overall, including required 
and recommended readings (too much); (b) the amount of time required each week to cover the material (underestimated); (c) the length of Course duration (could have been longer to allow coverage of the material); and (d) the variability in conceptual density of mini-lectures (some were seen to be too basic, and others too complex).

\section{Participant activity}

As well as feedback through the Exit Survey and Module Review Questions, facilitators also examined the amount and patterns of participant activity in the learning platform itself.

These activity statistics showed that there was an extremely wide range of participant engagement with Course content, from 556 visits by one participant and only five visits by another participant. Given this range, the median ( 85 visits) was taken as the most accurate indicator of engagement with the Course content, and for the group as a whole. The median number of visits for those doing the Course for credit was higher (median $=217$ ) than for those doing it purely for professional development (median $=66$ ), possibly reflecting the former group's learning strategy in support of successfully completing assessments for credit.

The level of participant engagement with the learning activities on the Course site was also used as a criterion for whether a Certificate of Completion, or a Certificate of Participation, would be issued at the end of the program. This was communicated through weekly announcements, to encourage enhanced engagement for those doing the Course solely for professional development (not credit).

Of all of the mechanisms within the course to enhance opportunities for participant engagement with each other, the Discussion Board proved to be the most used, with all 29 participants engaging with this at least once. Of those doing the Course for credit, only two participants were in the highest activity rate band, with the remainder lower than the median rate of participation with this tool - for the group as a whole. This suggests that engagement with the Discussion Board may not be a reliable indicator of course engagement, especially as participation was voluntary and not required for course credit. The for-credit cohort may have focused their time engaging with the content or readings in preparation for the assessment items, rather than with peers for sharing ideas or insights.

Only five participants (17\%) attempted to engage with the scheduled Collaborate Sessions (synchronous on-line classes) and so the decision was taken to cease these due to the technical difficulties experienced by some participants and other issues related to time zone differences and scheduling. There was also minimal engagement with Voice Thread which offered an ideal fusion of the benefits of the Discussion Board Forum (asynchronous) and Collaborate Sessions (synchronous), and which was actively promoted once the decision was taken to cease Collaborate Sessions.

Feedback on the Exit Survey was extremely positive regarding the relevance and impact of the Course for participants. Some key data are shown in Table 4 below.

Table 4. Items from exit survey relating to relevance to and/or impact on participants' practice

\begin{tabular}{ll} 
Agreement & \multicolumn{1}{c}{ Statement } \\
\hline $100 \%$ & Putting what I learned into practice will improve student outcomes \\
$97 \%$ & Having done this course, I can see areas where I can improve or learn more \\
$94 \%$ & The topics covered in the course are relevant for meeting my institution's goals \\
$88 \%$ & I will be able to put that I learned into practice \\
$87 \%$ & The Course will enhance my approach to student support and development \\
$87 \%$ & I gained new knowledge, insight or skills that are related to my profession \\
$75 \%$ & I learned more about relevant professional resources (e.g. journals and websites) \\
\hline
\end{tabular}


Results from Table 4 indicates that all participants agreed that if they applied the content of the course into their practice, it would improve student outcomes. Most participants (97\%) also noted that undertaking the course helped them to identify areas where they needed further training or where they could improve their practice. Results identified in Table 5 also indicate that the form and delivery of the Course were also highly rated on a number of indicators.

Table 5. Items from exit survey relating to form and/or delivery of the course

\begin{tabular}{ll}
\multicolumn{2}{c}{ Agreement } \\
\hline $94 \%$ & I was given opportunities to actively reflect on my practice \\
$94 \%$ & The course facilitator/s treated participants with respect \\
$94 \%$ & The instructor/s showed a good knowledge of the subject matter \\
$88 \%$ & I was given opportunities to actively reflect on my understanding and knowledge \\
$88 \%$ & I think there would be benefit in spreading the course over more weeks \\
$81 \%$ & I was given the opportunity to share ideas with other participants \\
\hline
\end{tabular}

When learning online, a key mechanism for participants to increased understanding is when learning activities provide opportunities for individual reflection (Means, Toyama, Murphy, Bakia, \& Jones, 2010). Within the course, $94 \%$ of participants agreed that they were provided opportunities to actively reflect on my practice $88 \%$ of participants agreed that they were provided opportunities to actively reflect on my understanding and knowledge. Overall, the literature supports the effectiveness of reflection activities as a means to improve online learning outcomes (Means, et al., 2010).

\section{Discussion}

\section{Participant feedback}

From the rich data provided by respondents to the Exit Survey, feedback on each Module, and unsolicited feedback from participants throughout the Course a number of themes emerged. First, it was clear that the Course had served a need, that is, for a formal program that offered professional development for those in student support and development roles in postsecondary education in Australia and New Zealand. How well it did that for each particular participant appeared to vary, according to their prior knowledge of, and experience in these sorts of roles, their expectations about study at this academic level (AQF Level 8), and their intentions in doing the Course (for credit or for professional development).

Survey responses and other feedback during the Course indicated issues with the Course content. Some participants reported that there was too much content, the depth and range of the content presented suited some participants but not others, and reference to similar content (within and across Modules) was viewed by some participants as redundant rather than as reinforcing or scaffolded learning. Some feedback that supported the too much content proposition was actually framed in the positive. For example, some participants stated they would have liked, or needed, more time to cover the content presented. A number of participants requested keeping the Course site open longer, which was done (three extra weeks) so they could cover all the material.

Participants also gave clear messages about the learning platform itself, and how this impacted their experience. The limitations of Blackboard in terms of user-friendly progress markers and movement between screens was evident in feedback, as was technical difficulties some participants experienced in using the engagement tools. As mentioned earlier, an aspect of the Course that warrants attention 
is the rather limited amount of active engagement of participants via the mechanisms in place to support peer-peer and participant-facilitator interaction.

While a couple of survey items asked participants about feedback on the assessment items, some participants would have valued more feedback on the self-reflection activities in the Course site itself (not assessable). Facilitators gave general feedback through weekly announcements and via posts on the Discussion Board Forum, but this may have seemed too general or some participants may not have routinely accessed these.

\section{Other feedback}

The Course facilitators were approached by a number of people who had not been able to participate in the pilot course. Reasons for not enrolling in the pilot of the Course included those who had missed the deadline for enrolment, were unable to secure funding, had withdrawn due to medical issues, or who wanted to do it in a subsequent offering when other commitments were more compatible with the time commitment. This interest also suggests a felt need for a Course such as this in some form or another.

\section{Facilitator insights}

This Course was developed, marketed and pitched to early career staff, or people new to student support and development roles, having come from other career fields. As this was a pilot of a new professional development "product", the Course was offered either for professional development only, or for $10 \mathrm{CP}$ credit towards a Graduate Certificate (AQF Level 8). On reflection, and from reading the Exit Survey and Module Review Question feedback, it is apparent that the Course was attempting to serve different purposes and would have been better offered as either a course for credit, or as professional development course. This would have enabled a more focussed approach, to not only content selection and delivery, but also to designing elements.

Asynchronous engagement between participants, and with facilitators, was available via the Discussion Board, Voice Thread, or (where participants had shared contacts details with each other) via email. It was evident from activity data that the Discussion Board was the most used tool. Participants also contacted the facilitators by email either in response to the weekly Announcement Email, or randomly when they had a question or suggestion. Given the unsuccessful attempt at synchronous (real-time) engagement using the Collaborate Session functionality, Voice Thread was proposed as a solution but had minimal uptake.

Feedback also suggested that some participants wanted to engage with other learners, and with facilitators, and others did not, or found this logistically difficult. This feedback is supported by previous research (see, for example, Croxton, 2014), and in the shared experience of academic colleagues teaching on-line in other units. The irony was not lost on the facilitators that one topic covered in the Course concerned engaging with on-line learners, and the importance of employing a suite of strategies to meet the needs of different learners' preferences and styles.

In the review of studies investigating whether and which learning strategies of on-line learners in a higher education environment impacted academic achievement mentioned earlier, Broadbent and Poon (2015) found that four strategies were significantly, but weakly associated with academic achievement - metacognition, time management, effort regulation and critical thinking. According to these researchers :

These findings suggest that on-line-students who make good use of their time, are conscious of their learning behaviour, are critical in their examination of content, and persevere in understanding the learning material despite challenges faced, are more likely to achieve higher academic grades in online settings $(2015$, p.11). 
While the introductory materials in the Course spoke to the issue of participants developing strategies to persist and succeed, and to overcome challenges in the on-line learning space, perhaps more attention could have been paid to articulating potential challenges, or even "teaching" participants how to learn on-line, and highlighting more of the research (Kuo, Walker, Schroder, \& Belland, 2014) around predictors of success in this learning mode early in the curriculum.

\section{Recommendations}

In terms of whether and how the Course might be offered in the future, a number of considerations are relevant. While the scope of the content reflected material covered in preparation programs elsewhere, any redevelopment of the Course, in whatever format this might take, would need to be informed by ongoing research about what such programs should be focussing on in the current climate for student affairs (Cooper, Mitchell, Eckerle \& Martin, 2016; Herdlein, Riefler \& Mrowka, 2013; Kimball \& Ryder, 2014; Latz, Ozaki, Royer \& Hornak, 2017; Lee \& Helm, 2013; Renn \& JessupAnger, 2008), and preferably as this relates to this geographical region and educational contexts in both countries. Further, other questions to be considered are, (a) What constitutes appropriate professional preparation and development? (Dickerson et al., 2011; Herdlein, Kline, Boquard \& Hadda, 2010); How is professional identity framed and formed? (Pittman \& Foubert, 2016); and (c) What is the role of professional associations in brokering this professional identity? (Janosik, Carpenter \& Creamer, 2006).

Another key recommendation would be to design the course with multiple pathways to cater for participants' diversity in terms of their level of experience in an SSDSP role as well as previous opportunities for professional development. Redesigning the course into focused modules could more effectively meet the needs of such a broad and diverse group.

Other considerations include ways to design and deliver the content that take account of good practice in on-line pedagogy. With the growth in on-line delivery of professional development, best practice in on-line learning needs to be constantly reviewed in light of emerging research around this, supported by both social network/communication as well as learning theory (Croxton, 2014), and reflecting on learner preferences for on-line collaboration (Muir et al, 2019). Consideration could also be given to other ways to evaluate learning and assess impact on participants beyond self-report on satisfaction and experience such as measuring change (pre and post involvement), on particular indicators such as self-efficacy (Shetty, Chunoo \& Cox, 2016).

\section{Conclusion}

There were a number of stakeholders involved in the development and delivery of this Course. Designing, building, convening, facilitating and evaluating it has proved a valuable learning, and indeed, a professional development, experience for all involved. For participants, involvement in the Course appears to have provided, for the most part, an opportunity for professional development that was tailored to the profession, had applicability to their practice, and that would contribute to the achievement of their institution's goals and to enhancing the student experience.

The value in the Course is evidenced by the formal recognition that participants received. All participants who gained a Certificate of Completion will also receive a "digital" badge retrospectively. This digital badge will recognise the elements of learning within the Course and may be used to demonstrate competency in the knowledge and skills covered in the course. A number of participants also opted to complete the additional formal assessment items and achieved $10 \mathrm{CP}$ credit towards a Graduate Certificate in Professional Learning offered by the host university (or potentially towards another award, depending on the institution). The viability of this form of professional development was also evident to two professional associations (ANZSSA and EPHEA - Equity 
Practitioners in Higher Education Australasia) that provided sponsorship by way of fee payment for members (via competitive application) to do the Course.

This program provided an opportunity for the host element (Professional Learning Hub) to expand its on-line delivery reach to a cohort that consisted of both international and national participants. This raised a number of considerations for the delivery team including finding a mutually suitable time for "real time" interaction, with the aim of maximising engagement and encouraging cohort discussion.

With the inaugural offering piloted and evaluated, the next steps will involve decisions around the future of the Course and what form it might take, and negotiations with various stakeholders about who will own, host, curate and deliver the next iteration. The Course could be updated, improved, streamlined and re-offered in the same 12-week format as a "for credit" option only. Alternatively, the content from the Course could be rewritten and modularised for those interested in professional development only or could be made available as "stackable micro-credentials" - where completion of a required number of micro-credentials could count towards credit.

If the leading professional associations concerned with student support and development in Australia and New Zealand (and possibly beyond these shores) see their role as contributing to advancing professional preparation and development of people who will and do work in these sorts of domains, then this pilot has provided a "first step" in assessing the need for, and the value and viability of such a program - and the indicators are promising.

It's been fantastic to have the opportunity to do this type of professional development...I've found so much of it extremely useful ${ }^{2}$.

\section{Acknowledgements}

This Course could not have been developed and delivered without the encouragement, input and expertise of the following people (and others too numerous to mention but to whom heartfelt gratitude is extended).

Colleagues - Brendan Mosley, Karen Davis, Jan Stewart, Anne-Marie Parsons, Dr Jim Elliot;

Presidents ANZSSA \& EPHEA, \& all guest presenters.

Host University - Sean Duffy, Antony Ley, Helen Trochoulias, and Todd Murray

\footnotetext{
${ }^{2}$ Unsolicited feedback from a Course participant via email to facilitator
} 


\section{References}

Australian Department of Education and Training (n.d.) - Higher Education. Retrieved from https://www.education.gov.au/search/site/higher\%20education

Australian Government. (2003). Federal register of legislation: Series C2004A01234. Retrieved from https://www.legislation.gov.au/Series/C2004A01234

Australian Government. (2013). Education services for overseas students act 2000: C2-13C000173. Retrieved from https://www.legislation.gov.au/Details/C2013C00173

Bondi, S. (2012). Students and institutions protecting whiteness as property: A critical race theory analysis of student affairs preparation. Journal of Student Affairs Research and Practice, 49(4), 397-414.

Broadbent, J., \& Poon, W.L. (2015). Self-regulated learning strategies \& academic achievement in on-line higher education learning environments: A systematic review. Internet and Higher Education, 27, 1-13

Coates, H., \& Ransom, L. (2011). Dropout DNA, and the genetics of effective support. Supporting participation and outcomes. Research Briefing. Australian Survey of Student Engagement (Vol. 11): Australian Council for Educational Research.

Connolly, S \& Diepenbrock, A. (2011). Perspectives of on-line graduate preparation programs for Student Affairs professionals. The American Journal of Distance Education, 25(2), 79-90 doi: 10.1080/08923647.2011.566441

Cooper, J., Mitchell, D.M. Jr., Eckerle, K., \& Martin, K. (2016). Addressing perceived skill deficiencies in Student Affairs graduate preparation programs. Journal of Student Affairs Research and Practice, 53(2), 107-117 doi:10.1080/19496591.2016.1121146

Creswell, J. (2017). Research design. Qualitative, quantitative and mixed methods approaches. London: SAGE Publications.

Croxton, R. A. (2014). The role of interactivity in student satisfaction and persistence in on-line learning, $M E R L O T$ Journal of On-line Learning and Teaching, 10(2), 314-325.

Department of Education \& Training (2018). Student services and amenities fee. Retrieved from www.education.gov.au/student-services-and-amenities-fee.

Department of Industry, Innovation \& Science (2019). Boosting innovation and science. Retrieved from www.innovation.gov.au/highereducation/Funding/Pages/default.aspx

Dickerson, A. M., Hoffman, J. L., Peper Anann, B., Brown, K. F., Vong, L. K., Bresciani, M. J., Monzon, R. \& Oyler, J. (2011). A comparison of senior student affairs officer and student affairs preparation program faculty expectations of entry-level professionals' competencies. Journal of Student Affairs Research and Practice, 48 (4), 463-479.

Herdlein, R. J., Kline, K., Boquard, B., \& Haddad, V. (2010). A survey of faculty perceptions of learning outcomes in master's level programs in higher education and student affairs. College Student Affairs Journal, 29(1), 33-45.

Herdlein, R. J., Riefler, L. \& Mrowka, K. (2013). An integrative literature review of Student Affairs competencies: A meta-analysis. Journal of Student Affairs Research and Practice, 50(3), 250-269.

Janosik, S. M., Carpenter, S. \& Creamer, D.G. (2006). Beyond professional preparation programs: The role of professional associations in ensuring a high-quality workforce. College Student Affairs Journal, 25(2), $228-237$.

Janosik, S. M., Carpenter, S. \& Creamer, D.G. (2006). Intentional professional development: feedback from Student Affairs professionals. NASPA Journal, 43(4), 127-146.

Kezar, A. (2003). Enhancing innovative partnerships: Creating a change model for academic and Student Affairs collaboration. Innovative Higher Education. 28(2), 137 - 156.

Kezar, A. (2011). What is the best way to achieve broader reach of improved practices in higher education? Innovative Higher Education, 36, 235-247.

Kezar, A., Eckel, P., Contreras-McGavin, M., \& Quaye, J. (2008). Creating a web of support: an important leadership strategy for advancing campus diversity. Higher Education, 55, 69-92.

Kimball, E. W., \& Ryder, A.J. (2014). Using history to promote reflections: a model for reframing student affairs practice. Journal of Student Affairs Research and Practice, 51(3), 298-310. 
Kuo, Y., Walker, A.E., Schroder, K.E.E, \& Belland, B.R. (2014). Interaction, internet self-efficacy and self-regulated learning as predictors of student satisfaction in on-line education courses. Internet and Higher Education, 20, 35-50. Retrieved from https://www.sciencedirect.com/science/article/pii/S1096751613000456

Latz, A.O., Ozaki, C.C., Royer, D.W. \& Hornak, A. M. (2017). Student affairs professionals in the community college: Critically examining preparation programs from a social justice lens. Journal of Student Affairs Research and Practice, 41 (11); 733-746.

Lee, J. J., \& Helm, M. (2013). Student affairs capitalism and early-career student affairs professionals. Journal of Student Affairs Research and Practice, 50(3), 290-307.

Ludeman, R. B., Osfield, K. J., Iglesias, E. H., \& Oste, D. S., \& Wang, H. (2009).Student Affairs and Services in Higher Education: Global Foundations, Issues and Best Practices. Proceedings of the World Conference on Higher Education and Research for Societal Change and Development, Paris, 2009. Accessed 20 November, 2018 from https://unesdoc.unesco.org/ark:/48223/pf0000183221

Manning, K., Kinzie, J. \& Schuh, J. H. (2014). One size does not fit all. Tradtional and innovative models of student affairs practice. ( $2^{\text {nd }}$ ed.). New York and London: Routeledge.

Means, B., Toyama, Y., Murphy, R., Bakia, M., \& Jones, K. (2010). Evaluation of evidence-based practices in online learning: A meta-analysis and review of online learning studies. Retrieved from: https://www2.ed.gov/rschstat/eval/tech/evidence-based-practices/finalreport.pdf

Ministry of Education, New Zealand Government. (2018). Tertiary Education Strategy 2014-2019. Retrieved from http://www.education.govt.nz/further-education/policies-and-strategies/tertiary-education-strategy/

Muir, T., Milthorpe, N., Stone, C., Dyment, J., Freeman, E \& Hopwood, B. (2019). Chronicling engagement: students' experience of online learning over time. Distance Education, Published online: 28 Apr 2019 https://doi.org/10.1080/01587919.2019.1600367

NASPA (Student Affairs Administrators in Higher Education) Graduate program directory. Retrieved from http://apps.naspa.org/gradprograms/

New Zealand Tertiary Education Commission. (n.d.). Retrieved from https://www.tec.govt.nz/teo/working-withteos/compulsory-student-services-fees/

Pittman, E. C. \& Foubert, J. D. (2016). Predictors of professional identity for student affairs professionals. Journal of Student Affairs Research and Practice, 53 (1), 13-25.

Renn, K. A. \& Jessup-Anger, E. R. (2008). Preparing new professionals: Lessons for graduate preparation programs from the National Study of New Professionals in Student Affairs. Journal of College Student Development, 49 (4), July-August, 319-335.

Shetty, R., Chinoo, V. S., \& Cox, B.E. (2016). Self -authorship in student affairs: A developmental paradox. Journal of Student Affairs Research and Practice, 53 (2), 131-145.

Stone, C. (2005). Promoting the integrated campus wide approach to first year student retention. Journal of the Australian and New Zealand Student Services Association, October, 2005, 33-40.

Stone, C. (2005a). Institutions Count but Resources Decide. In Transforming local political leadership (pp. 180-194). Palgrave Macmillan, London.

Teddlie, C., \& Tashakkori, A. (2009). Foundations of mixed methods research. Integrating quantitative and qualitative approaches in the social and behavioural sciences. Los Angeles, CA: SAGE.

\section{The authors may be contacted via \\ k.main@griffith.edu.au}

\section{Please cite this paper as:}

Peters, J., Main, K., Mooney, L., Ip, R., \& Noonan, D.(2019). Evaluating a pilot course - student support and development - a 360 degree professional learning opportunity.Journal of the Australian and New Zealand Student Services Association, 27(2), 201-216. https://doi.org.10.30688/janzssa.2019.09 